\title{
Is prophylactic treatment of contralateral blebs in patients with primary spontaneous pneumothorax indicated?
}

\author{
Shah-Hwa Chou, MD, ${ }^{\text {a,b }}$ Hsien-Pin Li, MD, ${ }^{\mathrm{a}}$ Jui-Ying Lee, MD, ${ }^{\mathrm{a}}$ Shun-Jen Chang, MD, ${ }^{\mathrm{c}}$ \\ Yen-Lung Lee, MD, ${ }^{\mathrm{a}}$ Yu-Tang Chang, MD, ${ }^{\mathrm{a}}$ Eing-Long Kao, MD, ${ }^{\mathrm{a}, \mathrm{b}}$ Zen-Kong Dai, MD, ${ }^{\mathrm{b}, \mathrm{d}}$ \\ and Meei-Feng Huang, $\mathrm{RN}^{\mathrm{a}}$
}

\begin{abstract}
Objectives: More than $50 \%$ of patients with primary spontaneous pneumothorax have contralateral blebs/bullae, and about a quarter will develop a contralateral pneumothorax. The purpose of this prospective study was to determine the need for elective treatment of asymptomatic contralateral blebs/bullae in patients presenting with primary spontaneous pneumothorax.
\end{abstract}

\begin{abstract}
Methods: From May 2006 through June 2008, results from 35 patients with ipsilateral primary spontaneous pneumothorax without contralateral blebs receiving unilateral video-assisted thoracic surgery, 35 patients with ipsilateral primary spontaneous pneumothorax with contralateral blebs receiving unilateral video-assisted thoracic surgery, and 16 patients with ipsilateral primary spontaneous pneumothorax receiving bilateral videoassisted thoracic surgery for positive contralateral blebs were collected. Their demographic and operating data were also recorded.

Results: There was no significant difference in age, gender, smoking percentage, body mass index $\left(\mathrm{kg} / \mathrm{m}^{2}\right)$, blood loss, and postoperative pain among groups. There was longer operative time and length of stay in group receiving bilateral surgery. Within the follow-up period of $16.68 \pm 9.91$ months (median, 17.50), no recurrence on either lung was found in the group operated on both sides, while contralateral occurrence was found in $17.14 \%$ of the group with ipsilateral primary spontaneous pneumothorax with contralateral blebs receiving unilateral video-assisted thoracic surgery within the period of $18.15 \pm 8.07$ months (median, 21).
\end{abstract}

Conclusion: The study showed that the preemptive video-assisted thoracic surgery for the contralateral blebs/ bullae effectively prevented the contralateral occurrence. (J Thorac Cardiovasc Surg 2010;139:1241-5)

Primary spontaneous pneumothorax (PSP) is troublesome for patients, due to its possibility of recurrence and even occurrence on the other side. According to other studies, the recurrence rate would be $16 \%$ to $50 \%$ on the ipsilateral side if there was no surgical intervention. ${ }^{1-6}$ Certainly, the rate would be increased with more episodes of attacks. ${ }^{6}$

Fifty-three percent of patients with unilateral PSP were found to have contralateral blebs/bullae, ${ }^{7}$ and the contralateral occurrence rate was around $15 \%{ }^{7,8}$ Ikeda and colleagues ${ }^{9}$ reported a rate of up to $50 \%$. More than that, Huang and associates ${ }^{10}$ reported all patients with contralateral occurrence had positive blebs/bullae in computed tomography (CT) scans of the lung.

\footnotetext{
From the Department of Surgery ${ }^{a}$; Faculty of Medical School, College of Medicine ${ }^{b}$; Department of Public Health School of Medicine ${ }^{c}$; and Department of Pediatric Chest Medicine, ${ }^{\mathrm{d}}$ Kaohsiung Medical University Hospital, Kaohsiung, Taiwan. Disclosures: None.

Received for publication Sept 24, 2008; revisions received June 10, 2009; accepted for publication July 16, 2009; available ahead of print Sept 18, 2009.

Address for reprints: Zen-Kong Dai, MD, Department of Pediatric Chest Medicine,

Kaohsiung Medical University Hospital, No. 100 Tz-You 1st road, Kaohsiung,

Taiwan (E-mail: shhwch@kmu.edu.tw).

0022-5223/\$36.00

Copyright (C) 2010 by The American Association for Thoracic Surgery

doi:10.1016/j.jtcvs.2009.07.047
}

The consensus for the common surgical indications of PSP mainly target the side of current attack. ${ }^{11}$ The correct attitude (consensus) in dealing with the contralateral blebs/ bullae is still disputed. ${ }^{7,10}$ This prospective study was to determine if single-stage bilateral surgery dealing with both the ipsilateral PSP and contralateral blebs/bullae would be effective in reducing the rate of contralateral occurrence and therefore be justifiable. No similar study has been reported in the literature.

\section{MATERIALS AND METHODS}

From May 2006 through June 2008, results from 86 consecutive patients with unilateral PSP who received video-assisted thoracic surgery (VATS) owing to (1) ipsilateral recurrence, (2) persistent air leak, or (3) radiologically demonstrated blebs/bullae were collected in this study. Patients with contralateral recurrence (second attack in the other lung) were excluded. High-resolution chest computed tomography scans (Brilliance 190P 2006; Philips, Cleveland, Ohio) were performed and evaluated before the operation. They were carefully read by the same radiologist and discussed with the thoracic surgeon. Blebs/bullae were defined as positive only when both doctors agreed.

Patients having contralateral blebs/bullae on high-resolution chest CT scan had their condition fully explained to them and their families: (1) the ipsilateral VATS had to be done for recurrence, persistent air leak, or radiologically demonstrated blebs/bullae; (2) the incidental finding of the contralateral blebs/bullae; or (3) the possibility and reported rate of contralateral occurrence. Contralateral VATS was offered on the same operation but 


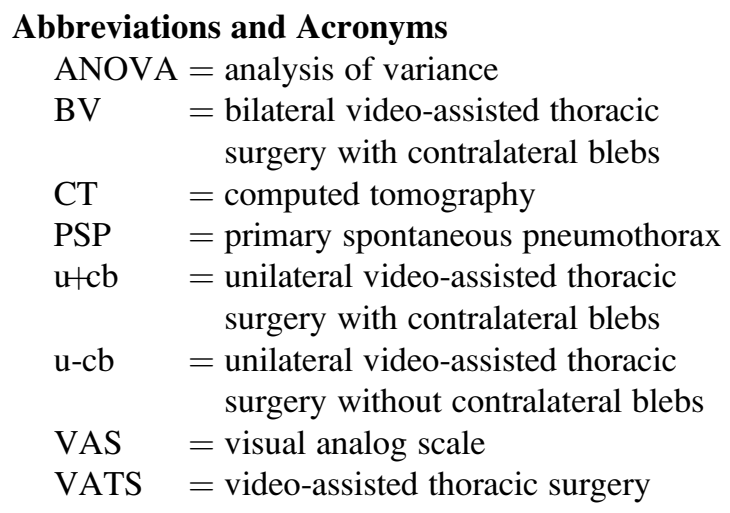

without any persuasion. Rejection or acceptance of the contralateral prophylactic VATS was decided solely by the patients and their families.

The study has been approved by the institutional review board, and all patients signed the informed consent before the operation.

\section{Surgical Technique (Needlescopic VATS)}

Surgery was performed in the lateral decubitus position under general anesthesia using double-lumen endotracheal tube. The lung operated on was collapsed. A 10-mm camera port was placed at the previous chest tube wound after thorough sterilization, or through a $1.0-\mathrm{cm}$ incision over the sixth or seventh intercostal space in the midaxillary line. Two 3-mm working ports were placed in the third intercostal space in the anterior axillary line and fifth intercostal space in the posterior axillary line. Using a 10-mm, 30-degree thoracoscopy (Karl Storz GmbH \& Co, Tuttlingen, Germany), the bleb or bulla was identified and fixed using a 3-mm endograsper. Then the $10-\mathrm{mm}, 30$-degree thoracoscope was discarded and removed. The 3-mm needlescope was inserted through the 3-mm working port for viewing. An EndoGIA endoscopic linear stapler (United States Surgical Corporation, Norwalk, Conn) was set at the previous $10-\mathrm{mm}$ wound to resect the lesion. In the absence of blebs, the apex of the upper lobe was resected with the EndoGIA linear stapler with the same procedure. ${ }^{11-14}$ The specimen was removed through the $10-\mathrm{mm}$ wound. Pleural abrasions for pleurodesis to prevent recurrence were performed under the vision of the needlescope using curved ring forceps with a piece of Marlex mesh (Bard Limited, Crawly, UK) through the 10-mm wound. Finally, the 10-mm, 30-degree thoracoscope was inserted again to check the stapling line and ensure the entire pleura were rubbed. At the completion of surgery, warm saline solution was instilled to check for air leaks. Before the lung reexpansion, a $32 \mathrm{~F}$ chest tube was placed under the vision of the needlescope. The puncture sites of 3-mm working ports were approximated with adhesive tapes (Steri-Strips; 3M Health Care, Borken, Germany) without suture. The contralateral lung was operated on with the same procedure.

After the VATS procedure, all patients were sent back to the ward. They were discharged after chest tube removal. Any discomfort or recurrence was carefully examined at the outpatient clinic visit. They were questioned by telephone of their current status (recurrence, scar formation, etc) before the editing of this paper. Their operative time, blood loss measured by weighing the gauze, postoperative pain in visual analog scale $(\mathrm{VAS})^{15}$ on the first postoperative day, hospital stay in days, complications, recurrence, and satisfaction with aesthetics were recorded.

\section{Statistical Analysis}

The patients were divided into 3 groups: (1) unilateral VATS, without contralateral blebs/bullae (u-cb); (2) unilateral VATS, with contralateral bleb/bullae (u+cb); and (3) bilateral VATS, with contralateral blebs/bullae (BV). Patients were analyzed for their descriptive variables (age at opera- tion, gender, smoking or not, and body mass index) by reviewing the medical charts. The differences were compared across the 3 groups of various surgical interventions using analysis of variance (ANOVA) for continuous variables and $\chi^{2}$ tests for categorical variables. Further analysis with Scheffé post hoc test was planned when the ANOVA showed that there was a statistical difference between groups. Results are expressed as means with standard deviations. SPSS for Windows version 12.0 was used for all statistics.

\section{RESULTS}

The study ended in June 2008 due to obvious statistical difference between bilateral and unilateral groups. There were 35 patients in group u-cb, 35 patients in group $u+c b$, and 16 patients in group BV. The gender, average age, percentage of smokers, and average body mass index in each group are shown in Table 1 with $95 \%$ confidence limits. There was no significant difference between the 3 groups $(P=.983, .792, .960$, and .675 , respectively). The operating data of the 3 groups are shown and compared in Table 2, along with $95 \%$ confidence limits. There were no statistical differences among the 3 groups on follow-up periods $(P=.503)$. The ANOVA showed that there was a statistical difference concerning blood loss during operation; however, further Scheffé post hoc analysis showed no significant differences between groups. The operating time (minutes) and length of stay of group BV were significantly longer than those of the other 2 groups $(P<.001)$, although only 1.3 days longer for the $\mathrm{BV}$ group. The postoperative pain in VAS was larger in group BV but of no significant difference. The percentage of contralateral occurrence for groups u-cb, u+cb, and BV were 2.86, 17.14, and 0 , respectively. The percentage for group u+cb was significantly higher than that of the other 2 groups.

For the entire series, recoveries were uneventful except for 4,3 , and 2 patients with ipsilateral prolonged air leak (>7 days) in groups $\mathrm{u}-\mathrm{cb}, \mathrm{u}+\mathrm{cb}$, and $\mathrm{BV}$, respectively. There were no other complications and no mortality in the entire series. No recurrence was found on the operated side. All patients were satisfied with the aesthetics.

Because recurrence of pneumothorax is time-related, a cumulative incidence curve for recurrence is shown in Figure 1. After 2 years of follow-up, the number of patients at risk is 24 .

\section{DISCUSSION}

It has been years since some centers used CT scans to determine the underlying etiology or detect apical blebs in cases of PSP. ${ }^{16-18}$ Since 2006, the CT scan has been implemented in our hospital as a routine examination for PSP. During a 26-month period, 51 of 86 patients with unilateral PSP were found to have contralateral blebs/bullae. The reported rate was $53.5 \%{ }^{7}$

The sensitivity of the plain chest radiography in detecting the underlying cause of PSP is $15 \%,{ }^{16}$ and that of the CT 
TABLE 1. Demographic variables of enrolled patients

\begin{tabular}{lcrrr}
\hline Enrolled patients & u-cb & u+cb & BV \\
\hline $\mathrm{n}$ & 35 & 35 & 16 \\
Gender (male, \%) & $85.71(74.12-97.31)$ & $85.71(74.12-97.31)$ & $87.50(76.54-98.46)$ \\
Age $(\mathrm{y})$ & $20.97 \pm 2.79(20.01-21.93)$ & $20.51 \pm 2.89(19.52-21.51)$ & $20.88 \pm 3.05(19.25-22.50)$ \\
Smoking $(\%)$ & $25.71(11.23-40.19)$ & $22.86(8.95-36.77)$ & .983 \\
BMI $\left(\mathrm{kg} / \mathrm{m}^{2}\right)$ & $19.49 \pm 0.96(19.16-19.83)$ & $19.28 \pm 1.04(18.92-19.64)$ & $19.42 \pm 1.16(18.80-20.03)$ & .792 \\
\hline
\end{tabular}

Values in parentheses are $95 \%$ confidence intervals. $u$ - $c b$, Unilateral VATS without contralateral blebs; $u+c b$, unilateral VATS with contralateral blebs; $B V$, bilateral VATS with contralateral blebs; VATS, video-assisted thoracic surgery. ${ }^{*}$ Significant difference from the 2 other groups.

scan is $85 \%$. The purpose of the latter includes determining the etiology of $\mathrm{PSP}^{16}$ and prediction of recurrence. ${ }^{8}$

In PSP, $70 \%$ to $88 \%{ }^{7,8,16}$ of ipsilateral blebs/bullae can be detected by CT scan, which also demonstrated lesions in the other lung $53.6 \%{ }^{7}$ to $66 \%{ }^{8}$ of the time. The rate of contralateral occurrence was around $5 \%$ to $15 \% .{ }^{7,8}$ However, the rate became significantly higher $(26.7 \%)^{7}$ if CT scans reveal contralateral blebs/bullae. In 2007, Huang and his colleagues ${ }^{10}$ reported all patients with contralateral recurrence had blebs/ bullae in high-resolution chest CTs of the lung.

According to this, single-stage bilateral VATS may be beneficial to patients to prevent or preempt subsequent occurrence on the other side, tubal thoracostomy, hospitalization, anesthesia, and operation.

The surgical indications for PSP are quite definite and well documented. However, the indications mainly focus on the current side of attack. There is still no consensus for what should be done to patients with radiologically demonstrated contralateral blebs/bullae. In this study, we compared the benefit and risk between patients undergoing bilateral VATS and unilateral VATS. Their demographic data and clinical features are of comparable basis. The operative time was significantly longer in group BV because 2 similar procedures were performed under 1 single anesthesia. Because the VATS for PSP is a simple procedure, and the patients were young and physiologically fit, the procedure of bilateral VATS is also considered to be safe. ${ }^{7}$

The hospital stay was longer in group BV; however, it was of no clinical significance. The blood loss through Scheffé post hoc analysis showed no significant difference among groups. It is reasonable that the postoperative pain in VAS was greater in group $\mathrm{BV}$, although our data revealed no significant difference $(P=.300)$.

All patients who had unilateral and bilateral VATS were satisfied with the scars and their cosmetic outcomes were similar.

The most important thing in this study is the comparison of the rate of contralateral occurrence between patients having contralateral VATS or not. Patients who had VATS on the contralateral blebs/bullae had no recurrence, and those receiving no VATS on the contralateral blebs/bullae showed $17.14 \%$ recurrence $(P=.038)$.

During the recent decade, VATS has almost become standard procedure for young patients with PSP worldwide. There is less postoperative pain and smaller scars. Since 2006, our team has started implementing needlescopic VATS instead of conventional VATS as the standard surgical treatment for PSP. The 3-mm needlescope and endograsper result in fewer neuromuscular injuries, and the scar is minimal. More importantly, the operative results are comparable to that of conventional VATS. ${ }^{19}$ The only weak point of needlescopic VATS is its narrower field of vision and poorer resolution. This would cause inconvenience and requires further verification of the lesions during the procedure; that is why a preoperative high-resolution CT scan is performed for detection and localization of the lung lesion. Additionally, experienced hands are advised to reduce technical error.

Before the era of minimally invasive surgery, the surgical indications for PSP were strict. Open thoracotomy, even axillary thoracotomy, can cause significant trauma, and recovery is long. Therefore, surgical intervention would be

TABLE 2. Clinical features of patients with operating data and long-term follow-up

\begin{tabular}{lccrc}
\hline & u-cb & u+cb & BV & $\boldsymbol{P}$ value \\
\hline Operative time (min) & $49.67 \pm 4.61(48.11-51.23)$ & $50.65 \pm 4.59(49.04-52.25)$ & $102.56 \pm 4.63 *(100.09-105.03)$ & $<.001$ \\
Blood loss (mL) & $17.30 \pm 10.02(13.90-20.69)$ & $18.09 \pm 6.63(15.77-20.40)$ & $23.40 \pm 6.26(20.07-26.74)$ & .046 \\
Postoperative pain in VAS & $7.40 \pm 0.96(7.08-7.73)$ & $7.62 \pm 1.10(7.23-8.00)$ & $7.87 \pm 0.88(7.39-8.34)$ & .300 \\
LOS (d) & $3.51 \pm 0.65(3.29-3.73)$ & $3.53 \pm 0.56(3.33-3.73)$ & $4.80 \pm 0.98 *(4.06-5.53)$ & $<.001$ \\
Contralateral occurrence (\%) & $2.86(0-8.38)$ & $17.14 *(4.66-29.63)$ & - & .038 \\
Follow-up (mo) & $18.05 \pm 7.72(15.44-20.69)$ & $18.15 \pm 8.07(15.33-20.97)$ & $16.68 \pm 9.91(11.40-21.97)$ & .503 \\
\hline Vin
\end{tabular}

Values in parentheses are $95 \%$ confidence intervals. $u$ - $c b$, Unilateral VATS without contralateral blebs; $u+c b$, unilateral VATS with contralateral blebs; $B V$, bilateral VATS with contralateral blebs; VATS, video-assisted thoracic surgery; VAS, visual analog scale; LOS, length of hospital stay. *Significant difference from the 2 other groups. 


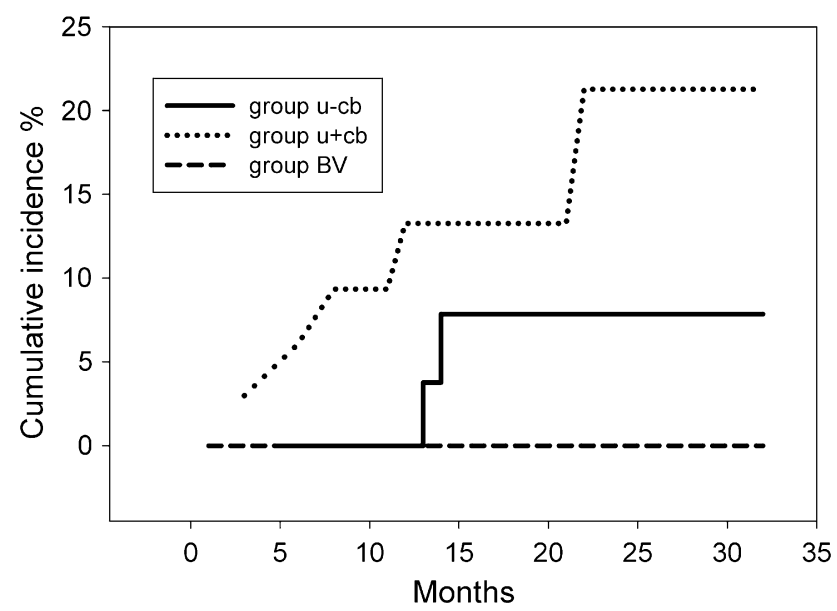

FIGURE 1. Cumulative incidence curve for recurrence. $u$ - $c b$, Unilateral VATS without contralateral blebs; $u+c b$, unilateral VATS with contralateral blebs; $B V$, bilateral VATS with contralateral blebs; VATS, video-assisted thoracic surgery.

more conservative. Over time, operative equipment has become more advanced. We can complete pulmonary procedures through 1 to 3 incisions of only 1 -cm length. Not just the trauma but also the scarring can be made minimal. Recently, some authors ${ }^{20-22}$ have suggested early operation so as to prevent recurrence. Some patients even request the operation to treat the first attack to have a definite treatment and therefore obtain a secure state of mind. ${ }^{23}$ Actually, bilateral surgery for unilateral PSP was advocated by Baronofsky 50 years ago. ${ }^{24}$

In this study, we noticed that bilateral surgery under the same anesthesia for patients with unilateral PSP has no increased risk. The pain in VAS is a little greater, but of little significance. Upon follow-up of $16.68 \pm 9.91$ months, no recurrence was found. All patients were satisfied with their scars. It exempts subsequent hospitalization, anesthesia, and operation. The most important thing is relief from fear of recurrence, and a secure state of mind can be obtained. Besides, the operative procedures and the reasons for intervention in the contralateral lung must be described and explained in full detail to the patients and informed consent has to be signed.

As for most studies, the conditions of the populations would not be absolutely the same. Therefore, comparing the outcome between the 2 treatment strategies is certainly not admissible. The authors are merely interested in presenting a new therapeutic idea under the aspiration of most possible surgical feasibility and greatest patient safety.

The main drawback of the present study remains the number of cases. As already mentioned, the intervention of the contralateral lung with blebs/bullae is decided solely by the patients themselves. Under no rationale could we advise or guide them to receive so-called "preventive" surgery. Therefore, the bilateral cases are limited. Future large-scale evaluations with longer follow-up periods are required.

\section{CONCLUSION}

Our experience showed that preemptive VATS to the contralateral blebs/bullae in the same operation to the ipsilateral PSP is beneficial to the patients. Not only are the subsequent hospitalization, anesthesia, and operation exempted, but also psychological burden of any unpredictable recurrence could be relieved.

\section{References}

1. Schramel FM, Postmus PE, Vanderschueren RG. Current aspects of spontaneous pneumothorax. Eur Respir J. 1997;10:1372-9.

2. Guo Y, Xie C, Rodriguez RM, Light RW. Factors related to recurrence of spontaneous pneumothorax. Respirology. 2005;10:378-84.

3. Baumann MH, Noppen M. Pneumothorax. Respirology. 2004;9:157-64.

4. Baumann MH, Strange C. Treatment of spontaneous pneumothorax: a more aggressive approach? Chest. 1997;112:789-804.

5. Chan SS, Lam PK. Simple aspiratory as initial treatment for primary spontaneous pneumothorax: results of 91 consecutive cases. J Emerg Med. 2005;28:133-8.

6. Ng CS, Lee TW, Wan S, Yim AP. Video-assisted thoracic surgery in the management of spontaneous pneumothorax: the current status. Postgrad Med J. 2006;82: 179-85.

7. Sihoe AD, Yim AP, Lee TW, Wan S, Yuen EH, Wan IY, et al. Can CT scanning be used to select patients with unilateral primary spontaneous pneumothorax for bilateral surgery? Chest. 2000;118:380-3.

8. Ouanes-Besbes L, Golli M, Knani J, Dachraovi F, Nciri N, EI Atrous S, et al. Prediction of recurrent spontaneous pneumothorax: CT scan findings versus management features. Respir Med. 2007;101:230-6.

9. Ikeda M, Uno A, Yamane Y, Hagiwara N. Median sternotomy with bilateral bullous resection for unilateral spontaneous pneumothorax, with special reference to operative indications. J Thorac Cardiovasc Surg. 1988;96:615-20.

10. Huang TW, Lee SC, Cheng YL, Tzao C, Hsu HH, Chang H, et al. Contralateral recurrence of primary spontaneous pneumothorax. Chest. 2007;132:1146-50.

11. Fry WA, Paape K. Pneumothorax. In: Thomas WS, Joseph L III, Ronald BP, Valerie WR, eds. General Thoracic Surgery. Volume 1. 6th ed. Philadelphia: Lippincott Williams \& Wilkins; 2005:794-805.

12. Jérôme M, Dan E, Bernard P, Aline M, Christophe P, Christine R, et al. Videoassisted thoracoscopic treatment of spontaneous pneumothorax: technique and results of one hundred cases. J Thorac Cardiovasc Surg. 1996;112:385-91.

13. Naunheim KS, Mack MJ, Hazelrigg SR, Ferguson MK, Ferson PF, Boley TM, et al. Safety and efficacy of video-assisted thoracic surgical techniques for the treatment of spontaneous pneumothorax. J Thorac Cardiovasc Surg. 1995;109: 1198-204.

14. Massard G, Thomas P, Wihlm JM. Minimally invasive management for first time and recurrent pneumothorax. Ann Thorac Surg. 1998;66:592-9.

15. Reading AE. Testing pain mechanisms in persons in pain. In: Wall PD, Melzack R, eds. Textbook of pain. Edinburgh: Churchill Livingstone; 2000. p.269-80.

16. Gupta KB, Mishra DS, Tandon S, Sindhwani G, Tanwar T. Role of chest CT scan in determining etiology of primary spontaneous pneumothorax. Indian J Chest Dis Allied Sci. 2003;45:173-7.

17. Warner BW, Bailey WW, Shipley RT. Value of computed tomography of the lung in the management of primary spontaneous pneumothorax. Am J Surg. 1991;162: $39-42$.

18. Kim J, Kim K, Shim YM, Chang WI, Park KH, Jun TG, et al. Video-assisted thoracic surgery as a primary therapy for primary spontaneous pneumothorax: decision making by the guideline of high-resolution computed tomography. Surg Endosc. 1998;12:1290-3.

19. Chen JS, Hsu HH, Kuo SW, Tsai PR, Chen RJ, Lee JM, et al. Needlescopic versus conventional video-assisted thoracic surgery for primary spontaneous pneumothorax: a comparative study. Ann Thorac Surg. 2003;75:1080-5.

20. Ben-Nun A, Soudack M, Best LA. Video-assisted thoracoscopic surgery for recurrent spontaneous pneumothorax: the long-term benefit. World J Surg. 2006;30:285-90.

21. Sawada S, Watanabe Y, Moriyama S. Video-assisted thoracoscopic surgery for primary spontaneous pneumothorax: evaluation of indications and long-term 
outcome compared with conservative treatment and open thoracotomy. Chest. 2005;127:2226-30.

22. Cole FH Jr, Cole FH, Khandekar A, Maxwell JM, Pate JW, Walker WA. Videoassisted thoracoscopic surgery: primary therapy for spontaneous pneumothorax? Ann Thorac Surg. 1995;60:931-5.
23. Chou SH, Cheng YJ, Kao EL. Is video-assisted thoracic surgery indicated in the first episode primary spontaneous pneumothorax. Interact Cardiovasc Thorac Surg. 2003;2:552-4.

24. Baronofsky ID, Warden HG, Kaufman JL, Whatley J, Hanner JM. Bilateral therapy for unilateral spontaneous pneumothorax. J Thorac Surg. 1957;34:310-22.

Access to The Journal of Thoracic and Cardiovascular Surgery Online is reserved for print subscribers!

Full-text access to The Journal of Thoracic and Cardiovascular Surgery Online is available for all print subscribers. To activate your individual online subscription, please visit The Journal of Thoracic and Cardiovascular Surgery Online, point your browser to http://www.mosby.com/itcvs, follow the prompts to activate your online access, and follow the instructions. To activate your account, you will need your subscriber account number, which you can find on your mailing label (note: the number of digits in your subscriber account number varies from 6 to 10). See the example below in which the subscriber account number has been circled:

\section{Sample mailing label}

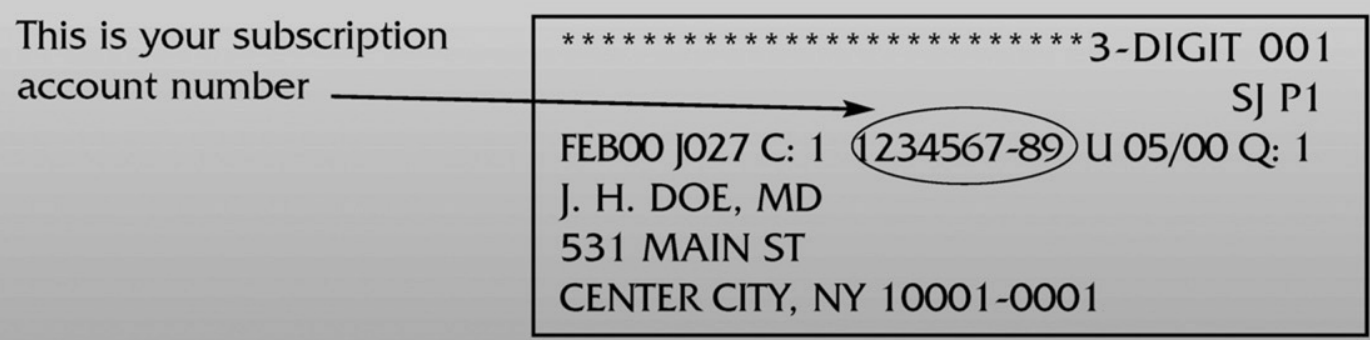

Personal subscriptions to The Journal of Thoracic and Cardiovascular Surgery Online are for individual use only and may not be transferred. Use of The Journal of Thoracic and Cardiovascular Surgery Online is subject to agreement to the terms and conditions as indicated online. 